\title{
Microwave Synthesis of Highly Aligned Ultra Narrow Semiconductor Rods and Wires
}

\author{
Asit Baran Panda, Garry Glaspell, M. Samy El-Shall * \\ Department of Chemistry, Virginia Commonwealth University, \\ Richmond, VA 23284-2006
}

\section{Supporting Information}
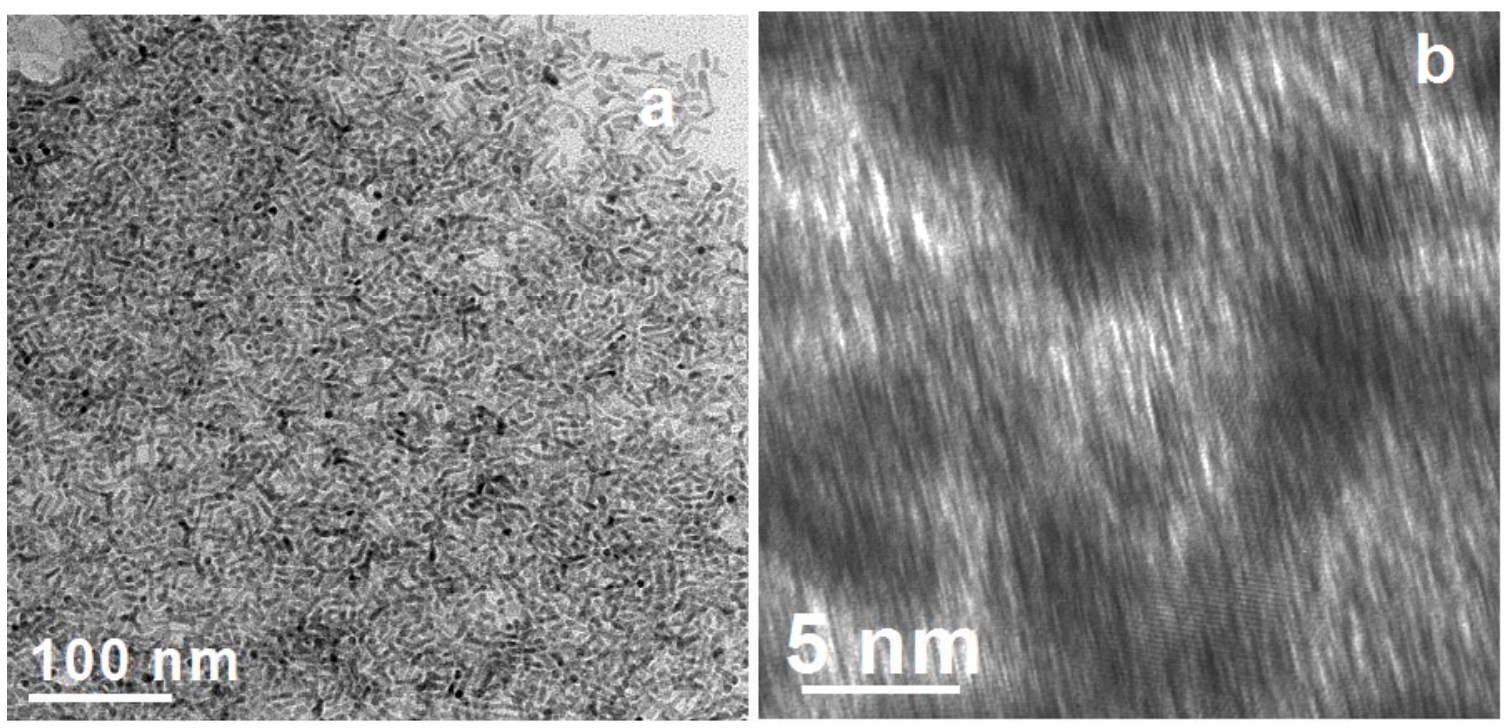

Figure (S1) Figure S-1: TEM (a) and HETEM (b) micrographs of CdS rods 

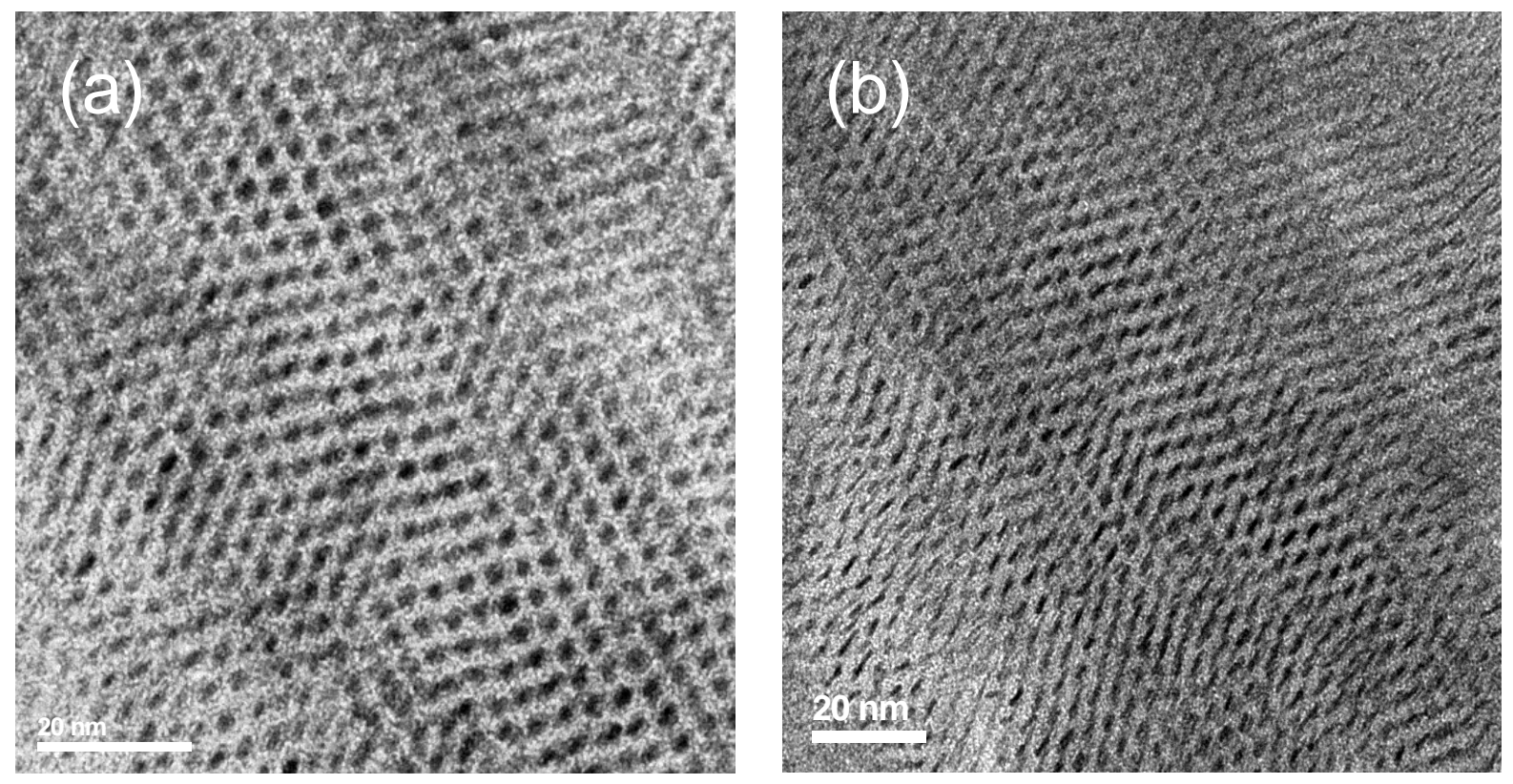

Figure S-2: TEM images of the intermediate more spherical (a) and elongated (b) ZnS nuclei 

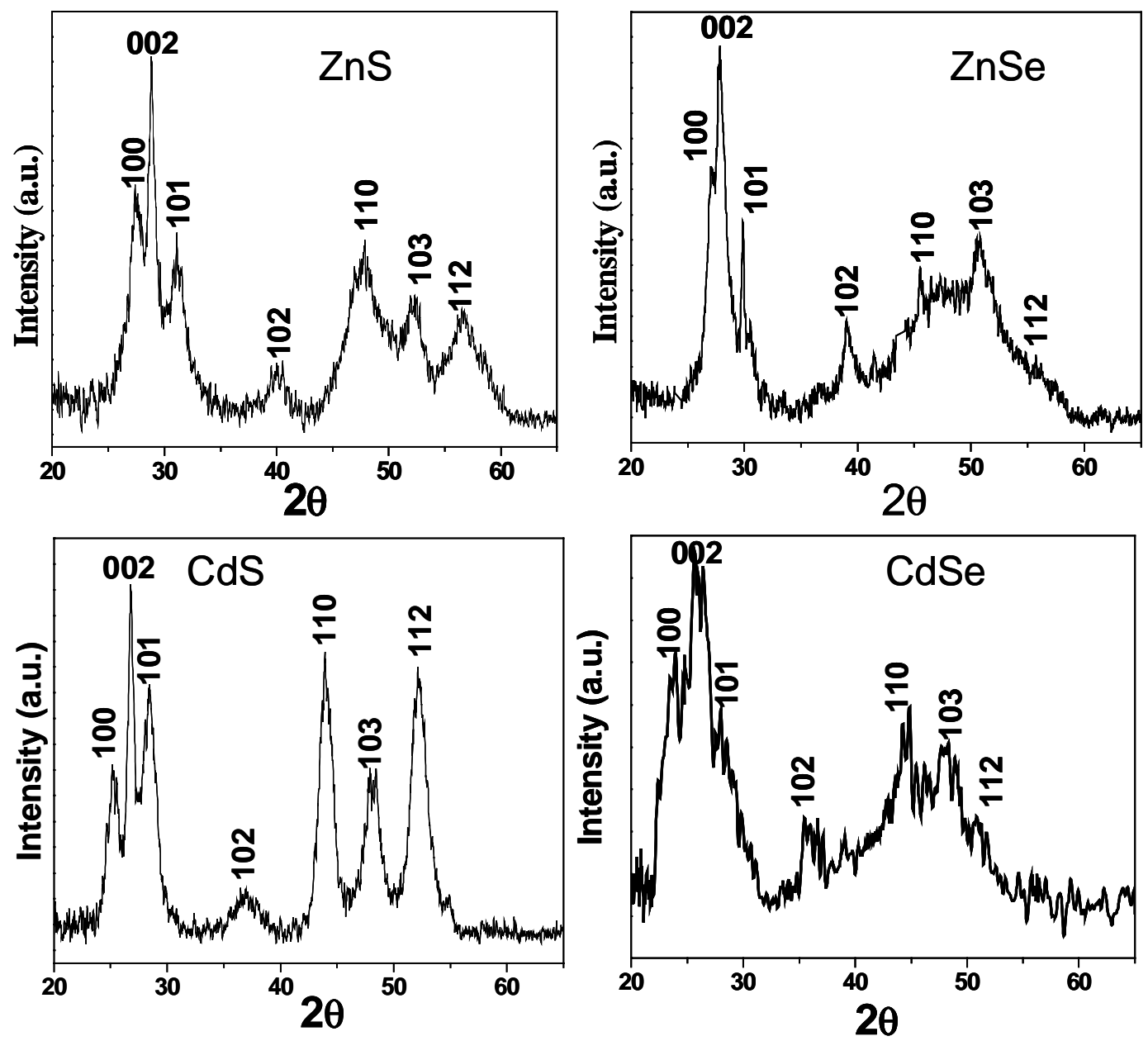

Figure S-3 X-ray diffraction (XRD) patterns of the synthesized ZnS, ZnSe, CdS and $\mathrm{CdSe}$ nano rods and wires. The XRD patterns demonstrate the high crystalline nature of the rods and wires and all the peaks match well the Bragg reflections of the standard wurtzite structure $\left(\mathrm{P}_{3} \mathrm{mc}, \mathrm{a}(\AA): 4.1320\right.$, c $(\AA): 6.7340$ for $\mathrm{CdS}$; a $(\AA): 3.8110$ c $(\AA): 6.2340$ for ZnS ; a $(\AA) 3.9960$ c $(\AA) 6.6260 \mathrm{ZnSe}$ and a $(\AA) 4.2990$ c $(\AA) 7.0100$ for CdSe). (ICDD data file, 03-065-3414 for CdS, 00-001-0677 for ZnS, 01-089-2940 for ZnSe and 03-065-3436 for CdSe). 


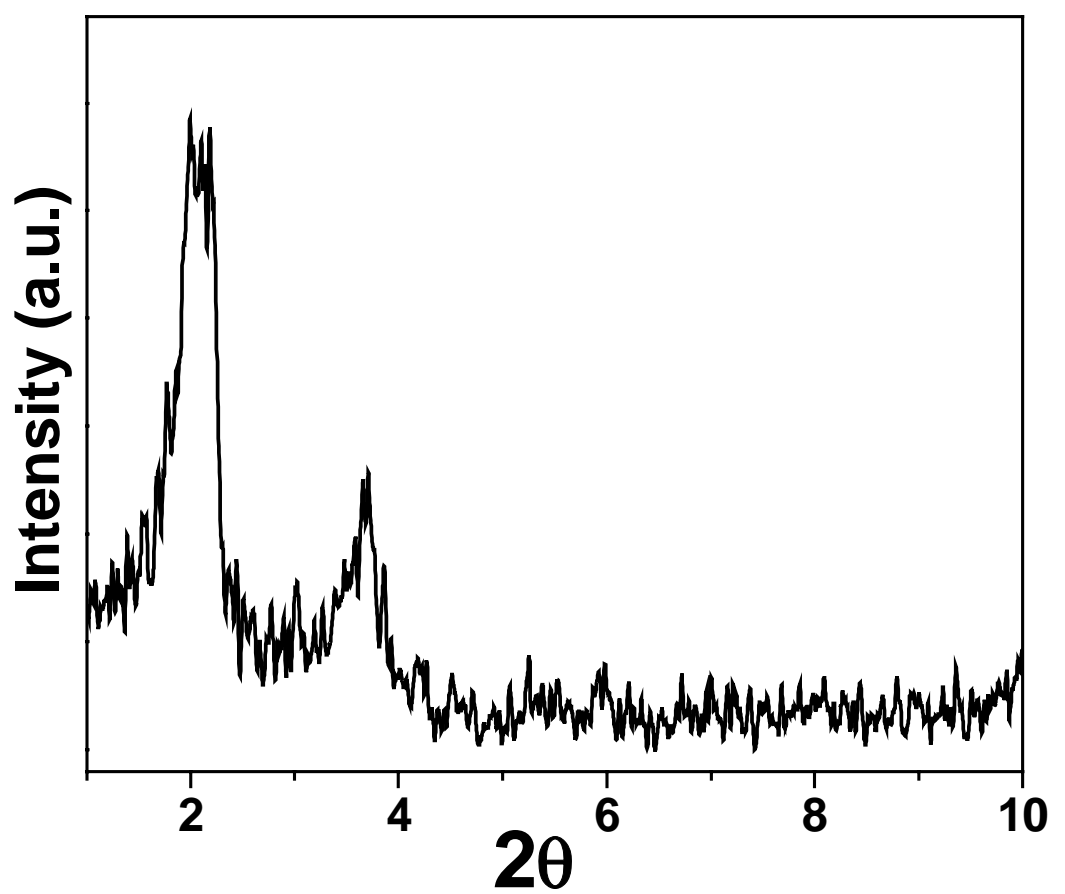

Figure S-4: Small Angle X-ray diffraction (XRD) of the synthesized $\mathrm{ZnS}$ nano rods. 